\title{
Evaluation of IoT-Based Grow Light Automation on Hydroponic Plant Growth
}

\author{
Yuda Prasetia ${ }^{1}$, Aji Gautama Putrada ${ }^{2}$, Andrian Rakhmatsyah ${ }^{3}$ \\ ${ }^{1}$ School of Computing Telkom University, Jl. Telekomunikasi No. 1, Bandung 40257, Indonesia \\ ${ }^{2}$ Advanced and Creative Networks Research Center, Telkom University, Jl. Telekomunikasi No. 1, Bandung 40257, Indonesia \\ ${ }^{3}$ School of Computing Telkom University, Jl. Telekomunikasi No. 1, Bandung 40257, Indonesia
}

\begin{tabular}{l} 
ARTICLE INFO \\
\hline Article history: \\
Received July 29, 2021 \\
Revised August 28, 2021 \\
Accepted September 06, 2021 \\
\hline Keywords: \\
Internet of things; \\
Grow light; \\
Hydroponic; \\
Real-time clock module; \\
T-test
\end{tabular}

\begin{abstract}
This research aims to design, create, and evaluate a hydroponic automation system by monitoring the quality of plant growth that uses LED grow lights and natural light conditions on hydroponics. Checking whether the proposed system has a significant effect on the bok choy hydroponic growth is also an important aspect and becomes the contribution of this paper. The contribution of this paper is by discussing in detail the automation of LED grow lights using RTC modules and relays while also discussing the significance of LED light performance in hydroponic growth. On the proposed hydroponic automation systems, light-feeding is done automatically, this can be carried out with the help of a real-time clock (RTC) module and relays. Furthermore, the monitoring function is carried out through temperature and humidity measurement sensors. The data obtained from the sensor will be stored in the database for research on plant quality. The results of a comparison test show that the LED grow lights are superior in terms of fresh weight, the number of leaves, and plant height respectively with an average value of 23.6 grams, 11.2 leaves, and $18.1 \mathrm{~cm}$ on the $30^{\text {th }}$ day. Compared to sunlight, respectively with an average value of 20.2 grams, 9.3 leaves, and $17.1 \mathrm{~cm}$ on the $30^{\text {th }}$ day. PDF calculation and t-test are used to calculate the growth significance. The results are that the $\mathrm{H} 0$ for fresh weight and leaf growth rate are rejected and the $\mathrm{H} 0$ for plant growth rate is not rejected. It can be concluded that the LED grow lights give significant effect on the fresh weight and leaf growth rate of IoTbased bok choy hydroponics if compared to sun light.
\end{abstract}

This work is licensed under a Creative Commons Attribution-Share Alike 4.0

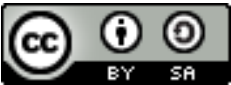

\section{Yuda Prasetia}

School of computing Telkom University, Jl. Telekomunikasi, Bandung 40257, Indonesia

Email: yudaaapras@student.telkomuniversity.ac.id

\section{INTRODUCTION}

The hydroponic system is a plant cultivation technique in which water replaces the role of the soil which is used as a medium for distributing nutrients and substances needed by plants [1]. Examples of important substances and nutrients are nitrogen $(\mathrm{N})$, phosphorus $(\mathrm{P})$ and potassium $(\mathrm{K})$ which are absorbed by plant roots [2]. The advantage of the hydroponic system is that growers have complete control over the environment, which includes its climate and its nutrient needs [3][4]. The hydroponic planting process can be done in 2 ways, namely outdoor hydroponics, and indoor hydroponics [5].

Sunlight is one of the factors that affect hydroponic growth [6]. Sunlight contains a spectrum of colors that can stimulate the photosynthetic process of hydroponic plants to grow [7]. However, due to some environmental conditions that are not ideal, nutrients for hydroponic plants from lighting may be lacking. To solve this problem, a system can be proposed where the sun's nutrients are replaced through the light-emitting diode (LED) grow lights that can produce a color spectrum like indoor sunlight [8].

Hydroponic planting can be automated with the help of internet of things (IoT) technology [9]. In an IoTbased automation system, monitoring the condition of hydroponic plants is carried out and controlled in the system through several sensors and actuators [10]. Built-in sensors allow monitoring and control of the 
humidity, temperature, and intensity of the environment light [11]. Data obtained from sensors is used to analyze crop yields for more optimal growth [12].

IoT devices and software applications are included to send and display system information online [13]. The application of IoT-based hydroponic automation in this study ensures that the data obtained is more efficient, the data obtained is said to be efficient because it is not done manually but replaced with the role of IoT [14]. Through automated systems and situation monitoring the data is obtained more because it is real-time [15]. This research aims to design, create, and evaluate a hydroponic automation system by monitoring the quality of plant growth that uses LED grow lights and natural light conditions on hydroponic bok choy. On the proposed hydroponic automation systems, light-feeding is done automatically, this can be carried out with the help of a real-time clock (RTC) module and relays. Furthermore, the monitoring function is carried out through temperature and humidity measurement sensors.

To evaluate the proposed system, a comparison is made with the conventional system. Thus, two systems are measured side by side. Three metrics are used to measure the growth of each hydroponic system, they are leaf count, plant height and fresh weight. To see the significance of the grow light in the plant growth, the ttest is used and the probability density function (PDF) of each growth is shown.

\section{RELATED WORK}

In some literature, the role of monitoring using IoT against hydroponics is very influential in the process of plant growth. IoT works efficiently with all hydroponic farming techniques. The data obtained from plants that use IoT is much better than with traditional techniques. According to Ali and Thakur, data obtained through IoT can also monitor and control hydroponic growth so that the resources used are more efficient [16]. All operations are controlled by Arduino microprocessors. The Internet of Things (IoT) which is integrated with an automation system can reduce manual labor and increase the ability to analyze data obtained through sensors [17]. Hydroponics connected with IoT systems in indoor media can be done at large or small scales, monitoring done through IoT systems provides the advantage to know the condition of plant growth with monitoring in real-time. The use of hydroponics indoors using IoT also gives an advantage to users because it does not require special land to plant [18]. The disadvantage of using IoT is that it requires maintenance and repair of the system to ensure the quality of the data obtained.

Another paper discusses the effects of irregular weather that makes hydroponic planting less optimal due to the lack of nutrients from sunlight so a method is needed that can overcome the problem of light needs. Monitoring is carried out to ensure consistency with optimal conditions for plant growth so that it can be seen a comparison of these light controls [19]. Extreme weather can change the temperature and humidity of the air, making it difficult for plants to grow [20]. Because light is very important for the life and growth of plants, then by looking at the quantity and quality of light we can see information about the growth and development of plants [21]. The role of sunlight as a trigger for photosynthesis for plant growth is indispensable in the process of plant growth. Lack of sunlight will make the maximum lack of growth in plants [22]. In addition to the lack of sunlight obtained by plants due to changes in weather, the temperature and humidity of the air will also change following the changes in the weather [23]. Temperature and humidity are also the factors that ensure the quality of hydroponics in meeting the needs of plants. Monitoring temperature and humidity using an automatic system can help hydroponic plant growth [24]. In this study it can be concluded that the plant's need for light affects the growth of plants. The advantage that can be taken is that to anticipate the lack of light due to extreme weather, alternative methods such as artificial light are needed. The drawback is how necessary an explanation of what types of light can be used if artificial light is needed to replace sunlight.

The other work related to this project is the use of technology as an alternative to agriculture in hydroponic cultivation uses artificial light integration to replace sunlight and overcome weather problems by Namgyel [13]. Planting can be done indoors using IoT systems for alternative sunlight solutions. The development of hydroponic systems using IoT can be linked to the manufacture of artificial light to replace the sun in the application of hydroponic planting. Internet of things (IoT) is implemented in a hydroponic system to facilitate the process of planting and monitoring via the web. The utilization of automated control systems on IoT delivers more efficient and secure results compared to manual methods [25]. The next related works about the consistent methods and checks to ensure indoor hydroponic plants can develop properly have been made by Kresnha and Wicahyani in 2019 [26]. Internet of Things (IoT) combined with automation systems can reduce human intervention [27]. The Internet of Things (IoT) is implemented in a hydroponic system to facilitate the process of planting and monitoring via the web [28]. Indoor hydroponic farming aids that can control and regulate the breeding of hydroponic plants using LED grow lights with ultraviolet light color. Replacement light such as LED grow light can be a source of lighting to overcome environmental problems and bad weather [29]. Monitoring plant conditions in real-time are very helpful in checking the state of hydroponic plants. The use of automation also plays a role in regulating the time required in the provision of LED growing lights. 
Related to the project by Esa, Abu Bakar, Abas, De Silva and Metali, the effect of different light intensity on plant growth has been analyzed showing almost double the increase with LED grow lights, compared to natural lighting against hydroponic growth [19]. The advantage that can be taken from this research is the use of artificial light to replace sunlight, in this study it can also be seen that the color of each light spectrum can affect hydroponic growth. The drawback is that the use of artificial light requires a closed room and periodic monitoring of the condition of the room is necessary.

In previous research, it has been explained how the influence of irregular weather that causes a lack of nutrients from sunlight, can be solved by artificial light that can replace sunlight and assisted by the role of IoT to monitor plant growth. In this study, it will be explained how to compare the growth of hydroponic bok choy plants using sunlight and LED grow lights. To ensure plant growth, a comparison will be made using a probability density function (PDF) so that it can be seen whether the quality of plant growth even after 30 days will be consistent or change.

\section{RESEARCH METHOD}

\subsection{Hydroponic System Design}

Research is carried out by looking for problems or phenomena that will be used as research topics. To find out the problem, a reference study was carried out on the topic of the problem taken. After obtaining the method to solve the problem, the design of the system used to solve the problem is carried out. Then the application of the system to the object of research is carried out. After the implementation, research will be carried out on the data obtained to draw conclusions from the solution to the research problem.

Fig. 1 shows a flowchart that explains the stages of how the system works. First, the system checks the RTC, if it is time to turn on the LED grow lights then the relay activates, and the LED lights turn on. If it is time to turn off the LED grow lights, the relay does otherwise. In the next step, the DHT 11 sensor checks the temperature and humidity values then all data from the sensor is sent by the NodeMCU to thinger.io. The data sent to thinger.io is stored in the database and can be viewed by the user on the dashboard.

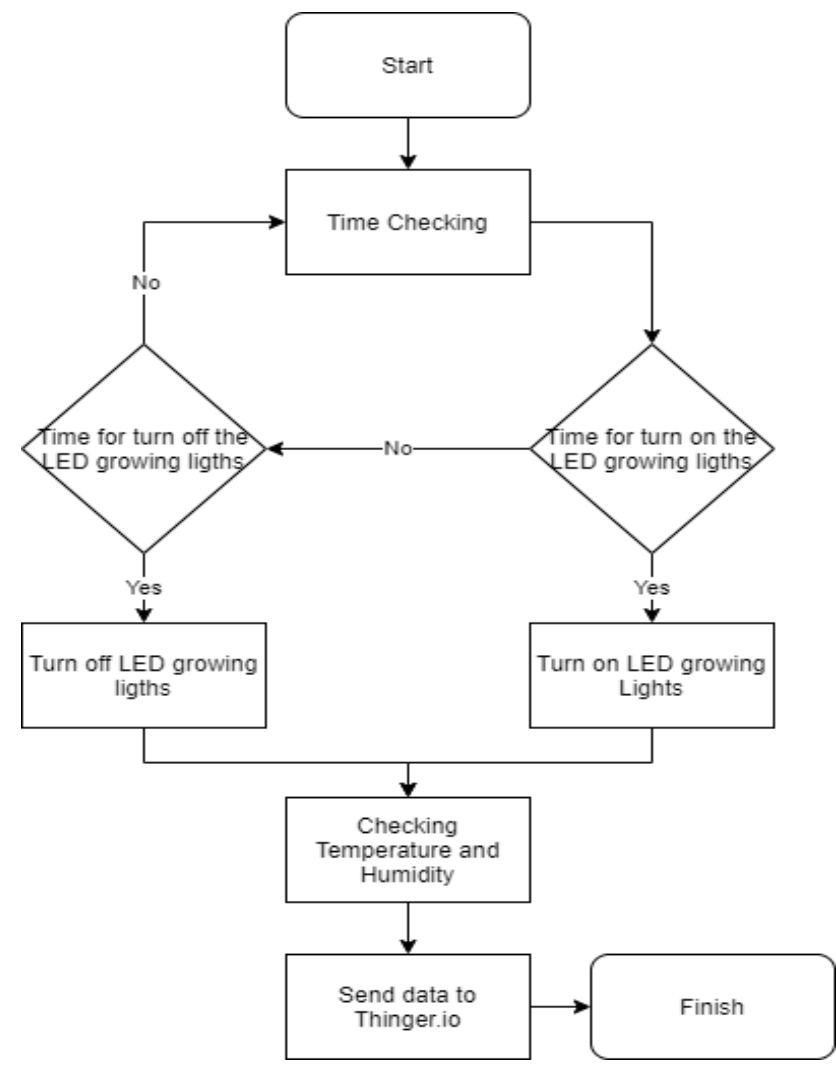

Fig. 1. Flowchart of the automated hydroponics system.

Fig. 2 shows a block diagram of a hydroponic system where there is an Arduino that sets the time to turn on the LED grow lights. The RTC module is used to set the time to turn on the LED grow lights and the Relay functions to turn on and off the LED grow lights according to the automation algorithm based on the time 
information submitted by the RTC module. In this study, it is determined that the relay turns on the lights when the RTC is at 06.00 AM and turned off at 06.00 PM.

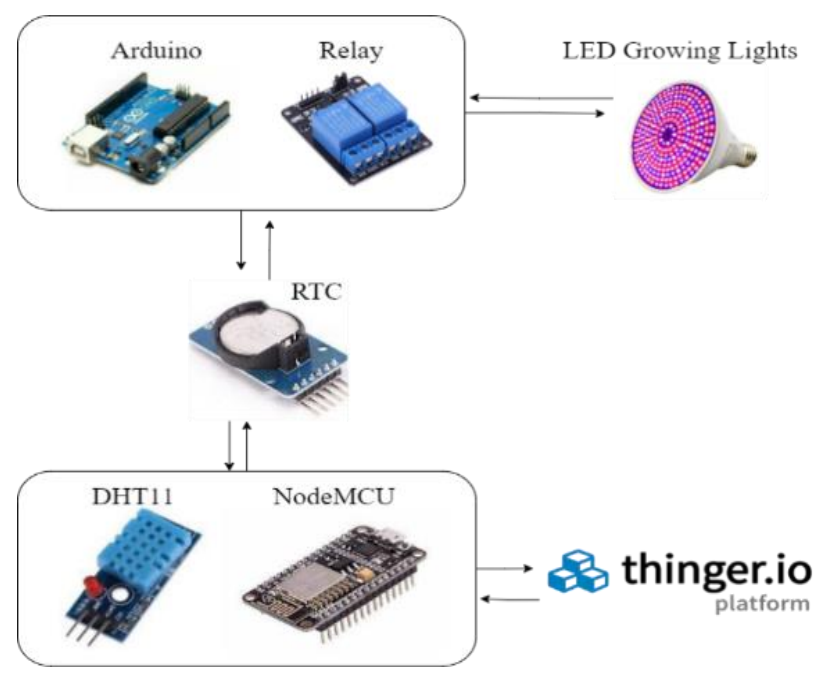

Fig. 2. Block diagram of hydroponic systems.

Both sensors and RTC are connected to a NodeMCU and a DHT 11 sensor. The DHT 11 is a temperature and humidity sensor. NodeMCU can send data to the server on the thinger.io platform via Wi-Fi communication. The data entered in thinger.io is recorded in the thinger.io database and displayed on the thinger.io dashboard to monitor the data measured by the sensor. Data obtained from sensors stored in the database thinger.io can be stored for 90 days and can be exported. Data obtained from sensors can be monitored directly in real-time. Parameters data obtained through sensors are sent to the web so that further and effective monitoring can be carried out [30]. The data sent directly from the sensor to the database can be researched so that the best conditions can be determined for the plant [31]. The reason for using Thinger.io as an IoT platform is because Thinger.io already has a live view system and has a database that can be used to store data so that Thinger.io can be used as a single platform without other platforms.

Fig. 3 shows the design of the hydroponic system uses a wick system where there is an axis that is used to connect the nutrient solution in a plastic container and growing media. The distance between the pot and the nutrient solution is not more than $1 \mathrm{~cm}$, the top of the lid of the container is made of 9 holes consisting of 3 holes in each row to place the pots which are about $5 \mathrm{~cm}$ apart. The wick uses flannel which easily absorbs the solution as a nutrient for hydroponics and where the roots grow, the nutrient solution is stirred manually once a day so that the nutrients in the water are evenly distributed. There are also LED grow lights as a light source that replaces sunlight which is designed with the IoT system in mind. The LED grow lights will be turned on for 12 hours, which is turned on at 06.00 AM and turned off at 06.00 PM.

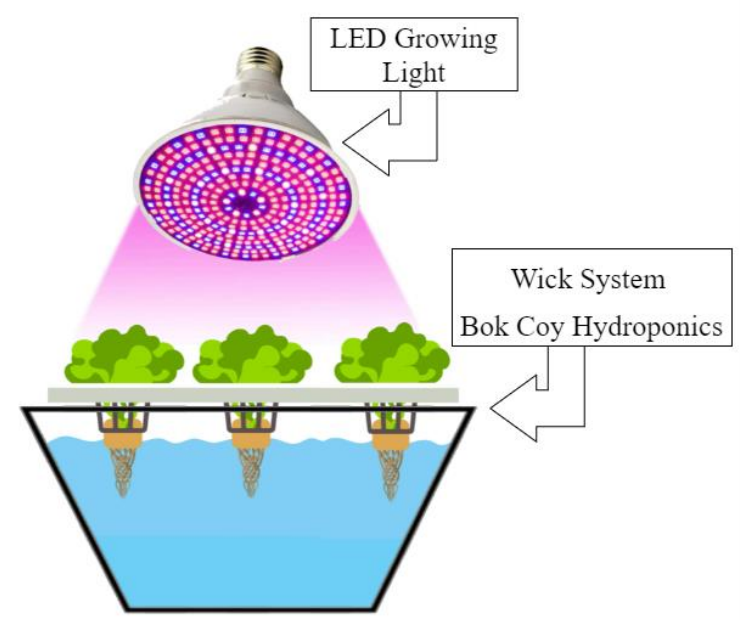

Fig. 3. Hydroponic System design and illustration of LED automation of grow lights. 
The plant used as research material is hydroponic bok choy which has large and short stems and wide leaf structures. Bok choy will be transferred to the wick system planting medium after 7-10 days after the seedlings or bok choy already has 4-5 leaves. Bok choy will be harvested when 30 days after planting with the characteristics of bright green leaf stalks and oval-shaped broad leaves.

\subsection{Hydroponic Grow Light Automation}

The hydroponic plant used is bok choy. There are two types of light sources given to hydroponic plants, namely light from LED grow lights and natural lights from the sunlight. LED grow lights are provided regularly and at the same time every day. Provisions and schedules for automatic lighting by the system can be seen in Table 1. The duration of providing LED grow lights is 12 hours per day. Light is given for 30 days. The fixed schedule for providing LED grow lights is from 06.00 am to $06.00 \mathrm{pm}$. Natural light is provided according to daily sunlight conditions.

Table 1. The Schedule of LED Grow Light Automation

\begin{tabular}{ll}
\hline \multicolumn{1}{c}{ Lighting System } & \multicolumn{1}{c}{ Light Time Schedule } \\
\hline LED grow lights & Turn on at 06.00 until 18.00 daily \\
\hline Sunlight & Follow the weather conditions according to the day \\
\hline
\end{tabular}

\subsection{Testing Metrics}

The test scenario is carried out on 2 systems, namely an outdoor system that implements LED grow lights automation and an indoor system that does not use LED grow lights automation. The hydroponic plants used are bok choy plants that are treated for 30 days using the wick system hydroponic technique. Some of the metrics measured and compared in this study are fresh weight, number of leaves, and plant height.

\section{Fresh Weight Testing}

The fresh weight of plants gives an idea of whether plants exposed to light from LED grow lights instead of sunlight can trigger plant growth or not. If effective, the fresh weight of the plant will be greater than the fresh weight of the plant without using LED grow lights. This test is not carried out periodically but is carried out when the plant has gone through growth for 30 days using a digital scale.

\section{Calculation of The Number of Leaves}

The number of leaves that grow can also describe whether the nutrients are well received by the plant or not. The number of leaves that describe growth comes from plants that have a higher number of leaves compared to other plants. The number of leaves is counted periodically once every 10 days until the $30^{\text {th }}$ day.

\section{Measurement of Plant Height}

Plants that absorb nutrients well grow tall. The plant heights of the two systems are averaged and then compared. Plant height measurements are carried out once every 10 days until the $30^{\text {th }}$ day.

\section{RESULTS AND DISCUSSION}

\subsection{System Implementation}

Fig. 4 shows the implementation of a hydroponic wick system with LED grow lights automation. In the figure, it is shown that LED grow lights are placed above the bok choy plants and gives an illustration of the lighting conditions. Wick hydroponic systems use a wick in a plant pot to distribute nutrients to a nutrient tank for plants. The use of LED grow light on the wick of the hydroponic system is implemented indoors where the light from the LED grow light replaces the role of sunlight. The LED grow light will be turned on at 06.00 AM and will be turned off at $06.00 \mathrm{PM}$.

Fig. 5 shows the IoT end-device system implementation for a wick hydroponic system with LED grow lights automation. The hardware consists of Arduino, RTC module, NodeMCU, DHT11 and relays. The relays are then connected to the power outlets and LED grow lights to do control functions based on the IoT system instructions.

Fig. 6 shows a mockup of the thinger.io dashboard page. On this page will display data information obtained from the sensor in real time. The data displayed is in the form of temperature, humidity, light status, time and graphs of temperature and humidity.

Fig. 7 shows a mockup of the thinger.io database page. This page will display data that has been stored in the thinger.io database through sensors connected to thinger.io. The data will be stored for 90 days on the thinger.io database. 

Vol. 7, No. 2, August 2021, pp. 314-325

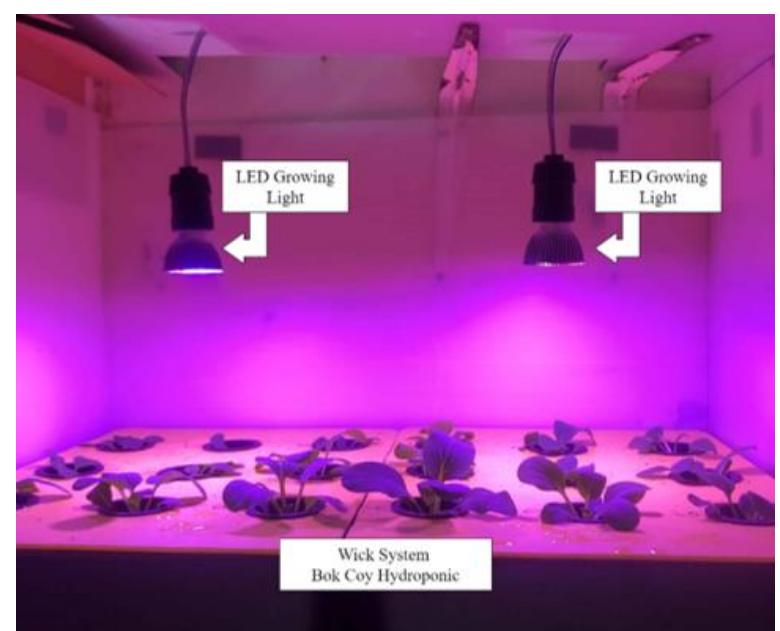

Fig. 4. Wick hydroponic system with LED grow lights automation implementation

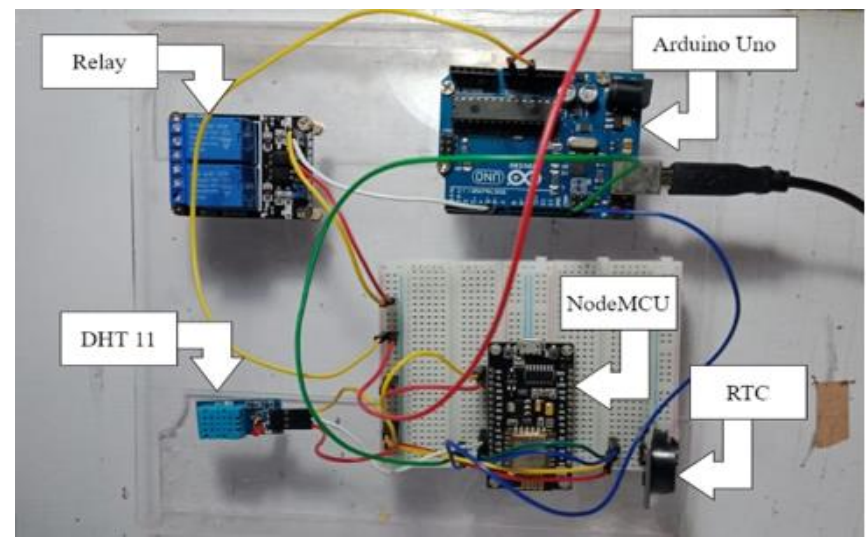

Fig. 5. IoT end-device of the LED grow lights automation system.

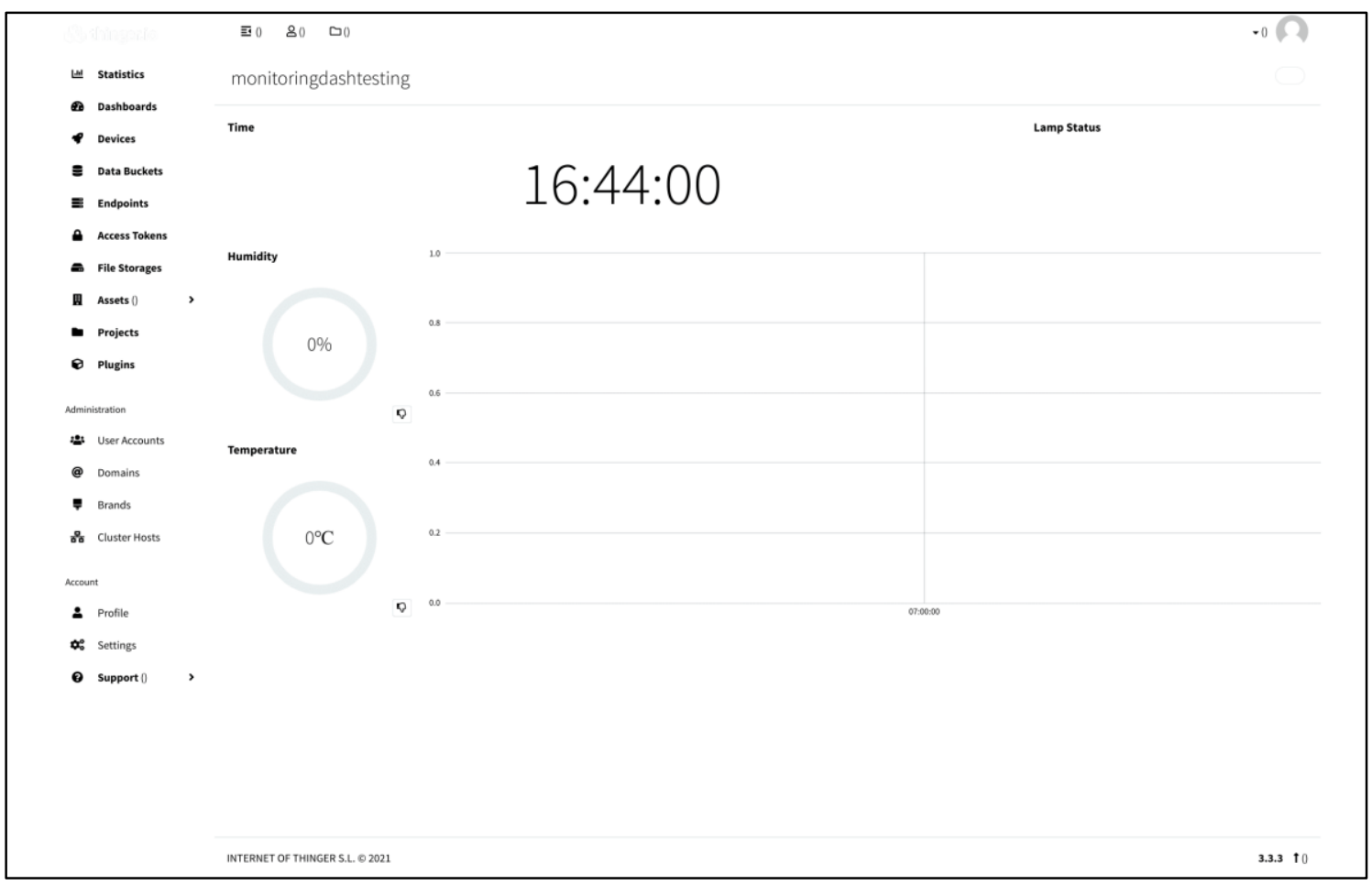

Fig. 6. Thinger.io dashboard page 


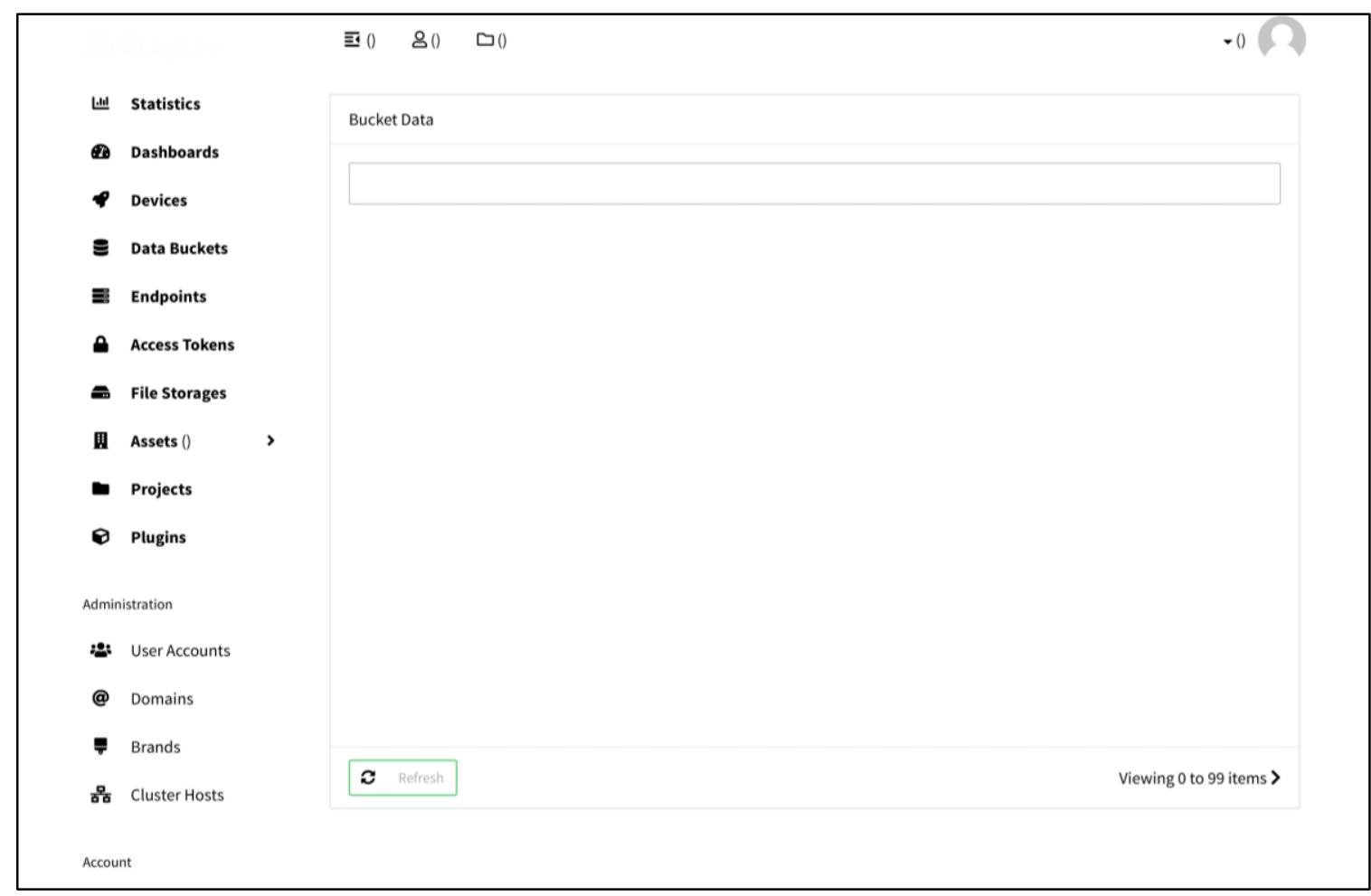

Fig. 7. Thinger.io database page

There are 4 pages on the thinger.io as the interface of the wick automation system grow lights. The first page shows the home page containing the location of the sensor as well as the number of many devices and databases used. The second page, as shown in the top image, shows data information from the temperature, humidity, and lamp status. The third page, as shown in the bottom image, contains data obtained by sensors stored in the database. The last page contains the history of the data have been downloaded and as a place to download the data stored on the database.

\subsection{Test Results}

Bok choy hydroponic wick system is planted for 30 days after the nursery period. The nutrients from the hydroponics are a mixture of $\mathrm{AB}$ mix nutrients and water with a ratio of $1000 \mathrm{ml}$ of water: $5 \mathrm{ml} \mathrm{A:} 5 \mathrm{ml} \mathrm{B}$. Comparison of hydroponic growth is carried out between hydroponics with an LED grow light automation system with hydroponics with natural sun light based on measurements of plant height, number of leaves and weight fresh plant. The following is a graph of the average value of bok choy hydroponic growth for 30 days.

In this study, the obstacles faced were software bugs and errors during 30 days of hydroponic growth data collection. The bug that is often found is when the status of the lights does not match the specified time provisions, thus affecting the data that is entered into the database. To work around this problem, the incorrect data is corrected manually. This error does not cause a delay in the data collection period.

The bok plot chart in Fig. 8 describes the comparison of fresh weight of hydroponic bok choy plants between LED grow lights and sunlight on the $30^{\text {th }}$ day. Hydroponics using LED grow lights produces a weight of $22-26 \mathrm{~g}$ with an average of $23.6 \mathrm{~g}$. This value is higher than hydroponics using sunlight which produces a weight of $18-23 \mathrm{~g}$ with an average of $20.2 \mathrm{~g}$.

The bok plot chart in Fig. 9 shows the comparison of the number of leaves from hydroponic bok choy between LED grow lights and sunlight recorded every 10 days for 30 days. On the $10^{\text {th }}$ day, hydroponics with LED grow lights produces 6-7 leaves and hydroponics with sunlight produced 5-7 leaves. On the $20^{\text {th }}$ day, hydroponics with LED grow lights produced 8-10 leaves and hydroponics with solar lights produced 7-8 leaves. On the $30^{\text {th }}$ day, hydroponics using LED grow lights produced $10-13$ leaves with an average of 11.2 leaves. This yield is higher than hydroponics with sunlight which produces 8 - 11 leaves with an average of 9.3 leaves.

The bok plot chart in Fig. 10 shows a comparison of the plant height from hydroponics bok choy between LED growing light and sunlight recorded every 10 days for 30 days. On day $10^{\text {th }}$, hydroponics using LED growing lights produces a plant height of $7-8 \mathrm{~cm}$ and hydroponics using sun lights produces $7-8 \mathrm{~cm}$. Day 
$20^{\text {th }}$, hydroponics using LED growing lights produces a plant height of $13-16 \mathrm{~cm}$ and hydroponics using sun lights produces $12-16 \mathrm{~cm}$. Day $30^{\text {th }}$, hydroponics using LED growing lights produces a plant height of $16-$ $20 \mathrm{~cm}$ with an average of $23.6 \mathrm{~cm}$. This value is higher than hydroponics using sunlight which produces a plant height of $15-19 \mathrm{~cm}$ with an average of $20.2 \mathrm{~cm}$.

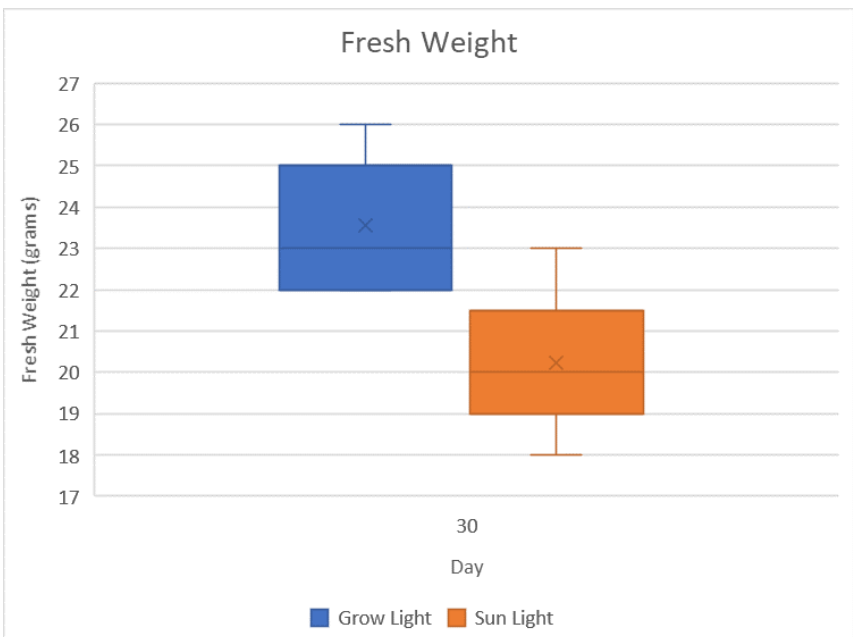

Fig. 8. Fresh weight comparison of LED grow light and sunlight

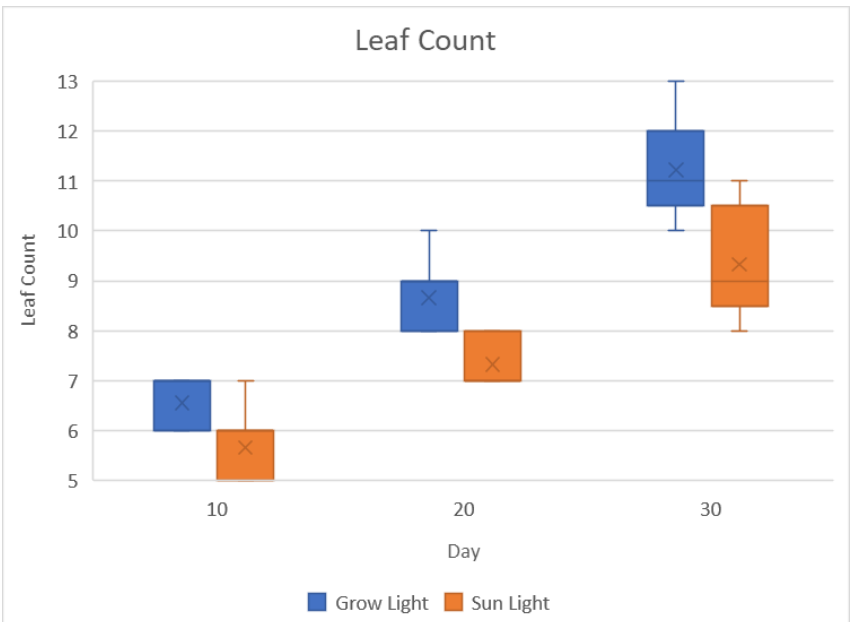

Fig. 9. Number of leaves comparison of LED grow light and sunlight

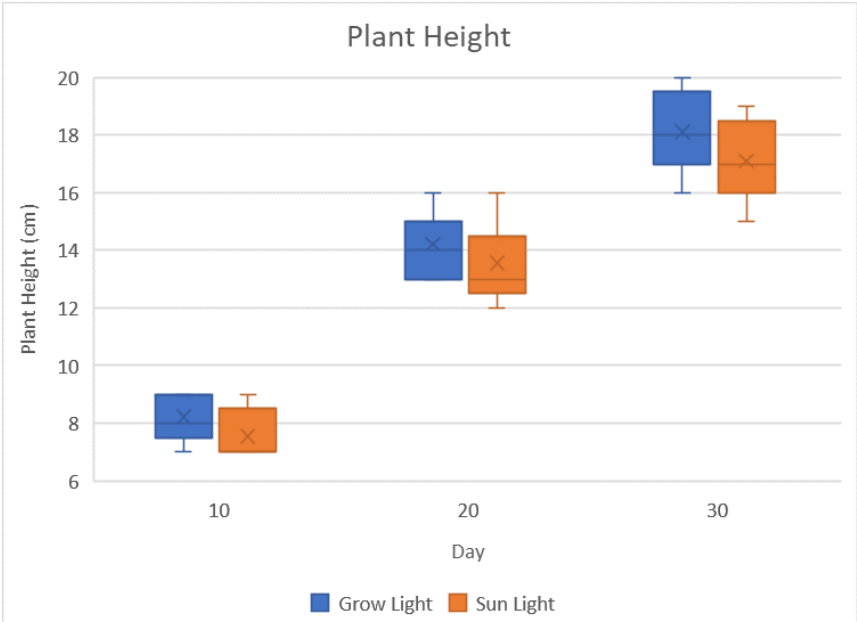

Fig. 10. Plant height comparison of LED grow light and sunlight 
The results of each method are furtherly discussed statistically. From each measurement, grow light always provides higher results but it is not certain if they are significantly higher. Whether or not they are significantly higher is tested and discussed with a t-test. First, to discuss the results, the growth rate of the number of leaves and plant height are calculated. The growth rate is calculated based on the curve slope equation as follow

$$
m=\frac{y_{2}-y_{1}}{x_{2}-x_{1}}
$$

where $m$ is the growth rate, $y_{2}$ is the next $\mathrm{n}^{\text {th }} 10$-day value, $y_{1}$ is the current $\mathrm{n}^{\text {th }} 10$-day value, $x_{2}$ is next $\mathrm{n}^{\text {th }} 10$ day, $x_{1}$ is current $\mathrm{n}^{\text {th }} 10$ days.

Then after the growth rate values are gathered, the PDF of fresh weight, leaf growth rate, and height growth rate based on their normal distribution are calculated and displayed. The equation is as follow

$$
f(x)=\frac{1}{\sigma \sqrt{2 \pi}} e^{-\frac{1}{2}\left(\frac{x-\mu}{\sigma}\right)^{2}}
$$

where $f(x)$ is the PDF, $\mu$ is the mean, and $\sigma$ is the standard deviation.

The results of each PDF can be seen in Fig. 11. From the figure, the difference in the distribution of each measurement can be seen. However, to calculate if the difference is significant, the t-test is used.
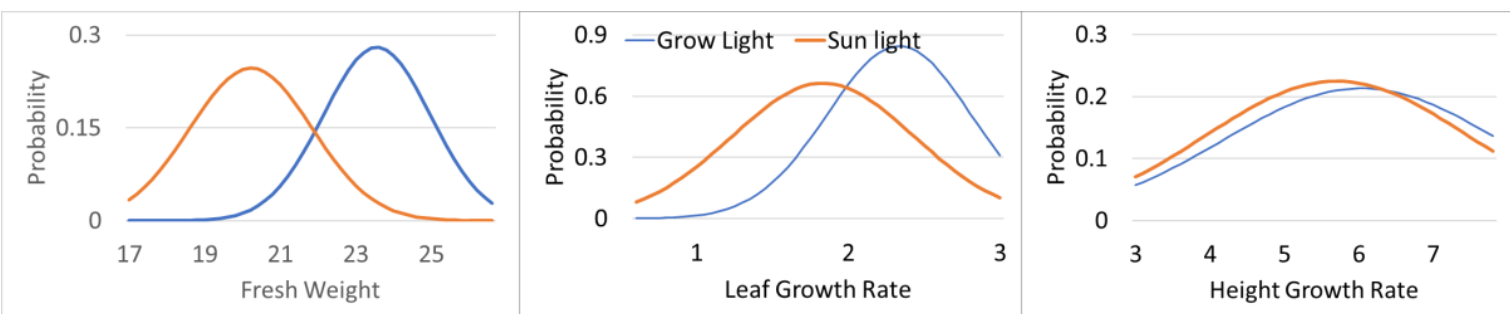

Fig. 11. PDF of fresh weight (left), leaf growth rate (center), and plant height growth rate (right)

T-test uses the t-stat value and is calculated using the equation as follow

$$
t=\frac{\bar{x}_{1}-\bar{x}_{2}}{s \sqrt{\frac{1}{n_{1}}-\frac{1}{n_{2}}}}
$$

where $t$ is the t-stat, $\bar{x}_{1}$ is the first distribution mean, $\bar{x}_{2}$ is the second distribution mean, $\mathrm{s}$ is the standard error, $\mathrm{n}_{1}$ is the number of observations of the first distribution, and $n_{2}$ is the number of observations of the second distribution.

Table 2 contains the results of the t-test calculation. From the table, the t-stat value is obtained from (3), the $\mathrm{t}$-critical value is obtained from the t-distribution table based on the degree of freedom (DoF) value and the $\alpha$ value. The null hypothesis, or $\mathrm{H}_{0}$, is where condition $\mu 1-\mu 2=0$ is met, which means there is no significant difference between the two distributions being compared. If $\mathrm{H}_{0}$ is rejected, it means $\mu 1-\mu 2 \neq 0$ which means that the two distributions being compared have significant differences. $\mathrm{H}_{0}$ is rejected if $\mathrm{t}$-stat is greater than $\mathrm{t}$ critical value or is less than -t critical value. If the inequality is not met, then $\mathrm{H}_{0}$ is not rejected

Table 2. T-Test Results of Fresh Weight, Leaf Growth Rate, and Height Growth Rate

\begin{tabular}{clcccc}
\hline No. & \multicolumn{1}{c}{ Metric } & T-stat & T critical value & $\mathbf{H}_{\mathbf{0}}$ & Difference \\
\hline 1 & Fresh weight & 4.202 & 2.145 & Rejected & Significant \\
\hline 2 & Leaf growth rate & 2.699 & 2.037 & Rejected & Significant \\
\hline 3 & Height growth rate & 0.659 & 2.007 & Not rejected & Not significant \\
\hline
\end{tabular}

Based on the table, for fresh weight, the $\mathrm{t}$-stat is greater than the $\mathrm{t}$-critical value, meaning that $\mathrm{H}_{0}$ is rejected, the conclusion is that the comparison of the two data on fresh weight has a significant difference. For leaf growth rate, the $\mathrm{t}$-stat value is greater than the $\mathrm{t}$-critical value, so $\mathrm{H}_{0}$ is also rejected. The conclusion is that the two data on leaf growth rates have significant differences. Finally, for the height growth rate, the t-stat value is smaller than the $t$ critical value, so it means that $\mathrm{H}_{0}$ is not rejected. The conclusion is that the two height 
growth rate data do not have a significant difference. Because there is no difference, it means that the value of the grow light height growth is higher than the sunlight is because it is explainable by chance only.

\subsection{Discussion}

This study discusses the effect of grow light on hydroponic growth, as has been discussed in research [8]. The difference of this research compared to related research and the contribution is that this research applies automation to grow lights utilizing an IoT-based system. Such a system can facilitate the work of hydroponic farmers. The IoT system built consists of a microcontroller and Wi-Fi communication using devices such as Arduino and NodeMCU, the same as those applied in reference [32]. The difference of this research compared to related research and the contribution is a performance comparison between IoT systems which is not discussed in the other paper. Hydroponics that utilizes IoT-based grow lights have been discussed in a paper [13] which also discusses the performance of LED lights in hydroponic growth.

The difference of this research compared to related research and the contribution is the detail in automation of LED grow lights using RTC modules and relays while also discussing the significance of LED light performance in hydroponic growth. Tests using a probability density function (PDF) will give results about the distribution of the measurements and use the t-test as a significant test of the data obtained.

\section{CONCLUSION}

A bok choy hydroponic system that implements LED grow lights automation with IoT architecture has been successfully implemented. The results of the comparison test show that the LED grow lights are superior in terms of fresh weight, the number of leaves, and plant height, respectively with an average value of 23.6 grams, 11.2 leaves, and $18.1 \mathrm{~cm}$ on the $30^{\text {th }}$ day, compared to sunlight, respectively with an average value of 20.2 grams, 9.3 leaves, and $17.1 \mathrm{~cm}$ on the $30^{\text {th }}$ day. Through the t-test, it can be calculated that the fresh weight and leaf growth rate of LED grow lights are significantly higher than that of sunlight, while the growth rate of LED grow light trees is not significant compared to sunlight.

\section{REFERENCES}

[1] M. Sabzian, A. Rahimikhoob, M. Mashal, S. Aliniaeifard, and T. Dehghani, "Comparison of water productivity and crop performance in hydroponic and soil cultivation using AquaCrop software* A case study of lettuce cultivation in Pakdasht, Iran," Irrig. Drain., 2021. https://doi.org/10.1002/ird.2600

[2] Triastinurmiatiningsih, P. Harsani, A. Qur'ania, and R. F. Hermawan, "Effects of deficiency nitrogen phosphorus potassium calcium in okra (Abelmoschus esculentus L. moench) through hydroponics," Int. J. Recent Technol. Eng., vol. 8, no. 3, pp. 4393-4396, 2019. https://doi.org/10.35940/ijrte.C5525.098319

[3] P. Srivani, C. Yamuna Devi, and H. Manjula, "A Controlled Environment Agriculture with Hydroponics: Variants, Parameters, Methodologies and Challenges for Smart Farming," 2019 15th Int. Conf. Inf. Process. Internet Things, ICINPRO 2019 - Proc., 2019. https://doi.org/10.1109/ICInPro47689.2019.9092043

[4] V. Permild, "HAVE: An interactive kitchen garden exploring the design of plant-based interfaces," Dissertation, Malmö universitet/Kultur och samhälle, 2018. https://www.diva-portal.org/smash/record.jsf?pid=diva2:1482074

[5] D. Eridani, O. Wardhani, and E. D. Widianto, "Designing and implementing the arduino-based nutrition feeding automation system of a prototype scaled nutrient film technique (NFT) hydroponics using total dissolved solids (TDS) sensor," Proc. - 2017 4th Int. Conf. Inf. Technol. Comput. Electr. Eng. ICITACEE 2017, 2018, pp. 170-175. https://doi.org/10.1109/ICITACEE.2017.8257697

[6] J. D. W. Lako, K. L. L. Sube, C. S. G. Lumori, J. P. Yengkopiong, J. A. M. Utong, S. A. Binyason, Y. S. L. Ngerja, M. K. Moilinga, T. F. Lado and A. H. Kheiralla, "Diversity and distribution of medicinal plants in the republic of South Sudan," World J. Adv. Res. Rev., vol. 07, no. 01, pp. 018-031, 2020. https://doi.org/10.30574/wjarr.2020.7.1.0165

[7] M. Vidović, F. Morina, S. Milić, B. Zechmann, A. Albert, J. B. Winkler, and S. V. Jovanović, "Ultraviolet-B component of sunlight stimulates photosynthesis and flavonoid accumulation in variegated Plectranthus coleoides leaves depending on background light," Plant, Cell Environ., vol. 38, no. 5, pp. 968-979, 2015. https://doi.org/10.1111/pce.12471

[8] E. G. Kulikova, S. Y. Efremova, N. Politaeva, and Y. Smyatskaya, "Efficiency of an alternative LED-based grow light system," IOP Conf. Ser. Earth Environ. Sci., vol. 288, no. 1, pp. 0-5, 2019. https://doi.org/10.1088/1755$1315 / 288 / 1 / 012064$

[9] A. A. Kori, K. N. Veena, P. I. Basarkod, and R. Harsha, "Hydroponics system based on IoT," Ann. Rom. Soc. Cell Biol., vol. 25, no. 4, pp. 9683-9688, 2021. https://www.annalsofrscb.ro/index.php/journal/article/view/3712

[10] R. Anjini, J. Jenifer, and M. A. M. C. Blessy, "IoT Based Automated Hydroponics Greenhouse Monitoring," Int. J. Adv. Res. Sci. Commun. Technol., vol. 4, no. 2, pp. 671-681, 2021. https://doi.org/10.48175/IJARSCT-960

[11] L. Kamala K., S. A. Alex, and A. Kanavalli, "Survey on Various Techniques That Is Involved in Monitoring Hydroponic Plants,” SSRN Electron. J., 2021. https://doi.org/10.2139/ssrn.3861431

[12] M. S. Gour, V. Reddy, Vamsi M., Sridhar N., Vishuvardhan and V. T. Ram, "IoT based Farming Techniques in Indoor Environment: A Brief Survey," 2020 5th International Conference on Communication and Electronics Systems (ICCES), 2020, pp. 790-795. https://ieeexplore.iee.org/abstract/document/9137950 
[13] T. Namgyel et al., "IoT based hydroponic system with supplementary LED light for smart home farming of lettuce," ECTI-CON 2018 - 15th Int. Conf. Electr. Eng. Comput. Telecommun. Inf. Technol., 2018, pp. 221-224. https://doi.org/10.1109/ECTICon.2018.8619983

[14] D. Wu, X. Xie, X. Ni, B. Fu, H. Deng, H. Zeng, and Z. Qin, "Software-Defined Edge Computing: A New Architecture Paradigm to Support IoT Data Analysis," arXiv preprint, arXiv: 2104.11645, 2021. https://arxiv.org/abs/2104.11645

[15] P. Defourny et al., "Near real-time agriculture monitoring at national scale at parcel resolution: Performance assessment of the Sen2-Agri automated system in various cropping systems around the world," Remote Sens. Environ., vol. 221, pp. 551-568, 2019. https://doi.org/10.1016/j.rse.2018.11.007

[16] M. F. Ali, P. Thakur, P. Mendiratta, and N. Gupta, "IoT-based solar hydroponics farming," Proc. 2019 6th Int. Conf. Comput. Sustain. Glob. Dev. INDIACom 2019, pp. 927-931, 2019. https://ieeexplore.ieee.org/abstract/document/8991183

[17] A. R. Yanes, P. Martinez, and R. Ahmad, "Towards automated aquaponics: A review on monitoring, IoT, and smart systems," J. Clean. Prod., vol. 263, p. 121571, 2020. https://doi.org/10.1016/j.jclepro.2020.121571

[18] N. Bakhtar, V. Chhabria, I. Chougle, H. Vidhrani, and R. Hande, "IoT based hydroponic farm," Proc. Int. Conf. Smart Syst. Inven. Technol. (ICSSIT), 2018, pp. 205-209. https://doi.org/10.1109/ICSSIT.2018.8748447

[19] M. Z. Esa, M. S. A. Bakar, Pg E. Pg Abas, L. De Silva, and F. Metali, "IoTs Hydroponics System: Effect of light condition towards plant growth," The 1st International Conference on Computer Science and Engineering Technology (ICCSET), 2018, pp. 342-349. https://doi.org/10.4108/eai.24-10-2018.2280609

[20] K. Ngadimon, S. M. Basharie, K. Othman, and T. Raman, "Lighting and Air Temperature Monitoring and Control of Hydroponic System using Internet of Things (IoT)," Multidiscip. Appl. Res. Innov., vol. 2, no. 1, pp. 266-276, 2021. https://publisher.uthm.edu.my/periodicals/index.php/mari/article/view/382

[21] Deepika, Ankit, S. Sagar, and A. Singh, "Dark-Induced Hormonal Regulation of Plant Growth and Development," Front. Plant Sci., vol. 11, no. 581666, pp. 1-10, 2020. https://doi.org/10.3389/fpls.2020.581666

[22] T. Schumann, S. Paul, M. Melzer, P. Dörmann, and P. Jahns, "Plant growth under natural light conditions provides highly flexible short-term acclimation properties toward high light stress," Front. Plant Sci., vol. 8, no. 681, pp. 118, 2017. https://doi.org/10.3389/fpls.2017.00681

[23] T. D. Drezner, "The importance of microenvironment: Opuntia plant growth, form and the response to sunlight," $J$. Arid Environ., vol. 178, p. 104144, 2020. https://doi.org/10.1016/j.jaridenv.2020.104144

[24] A. A. Angga Dwipa, I. G. P. W. Wedashwara W, and A. Zubaidi, "Rancang Bangun Sistem Conditioining Udara Berbasis IoT pada Studi Kasus Tanaman Selada Hidroponik," J. Comput. Sci. Informatics Eng., vol. 4, no. 1, pp. 1625, 2020. https://doi.org/10.29303/jcosine.v4i1.297

[25] S. A. Karimah, A. Rakhmatsyah, and N. A. Suwastika, "Smart pot implementation using fuzzy logic," J. Phys. Conf. Ser., vol. 1192, no. 1, 2019. https://doi.org/10.1088/1742-6596/1192/1/012058

[26] P. E. Kresnha, N. Latifhah, and A. Wicahyani, "Automasi Hidroponik Indoor Sistem Wick dengan Pengaturan Penyinaran Menggunakan Growing Lights dan Pemberitahuan Nutrisi Berbasis SMS Gateway," Semin. Nas. Teknol., pp. 1-8, 2019. https://jurnal.umj.ac.id/index.php/semnastek/article/view/5229

[27] V. Palande, A. Zaheer, and K. George, "Fully Automated Hydroponic System for Indoor Plant Growth," Procedia Comput. Sci., vol. 129, pp. 482-488, 2018. https://doi.org/10.1016/j.procs.2018.03.028

[28] R. Lakshmanan, M. Djama, S. K. Selvaperumal, and R. Abdulla, "Automated smart hydroponics system using internet of things," Int. J. Electr. Comput. Eng., vol. 10, no. 6, pp. 6389-6398, 2020. https://doi.org/10.11591/ijece.v10i6.pp6389-6398

[29] H. S. Chua, L. S. Wei, S. Paramasivam, T. T. Goh, and G. C. Chen, "Effect of artificial night lighting on the growth of loose head lettuce in hydroponic system," Sains Malaysiana, vol. 49, no. 12, pp. 2891-2900, 2020. https://doi.org/10.17576/jsm-2020-4912-02

[30] W. S. Aung and S. A. N. Oo, "Monitoring and Controlling Device for Smart Greenhouse by using Thinger.io IoT Server," Int. J. Trend Sci. Res. Dev., vol. 3, no. 4, pp. 1651-1656, 2019. https://www.ijtsrd.com/papers/ijtsrd25212.pdf

[31] M. R. Kulkarni, N. N. Yadav, S. A. Kore-Mali, and S. R. Prasad, "Greenhouse automation using IoT," International Journal of Scientific Development and Research (IJSDR), vol. 5, no. 4, pp. 239-242, 2020. https://www.ijsdr.org/papers/IJSDR2004041.pdf

[32] P. Sihombing, N. A. Karina, J. T. Tarigan, and M. I. Syarif, “Automated hydroponics nutrition plants systems using arduino uno microcontroller based on android," J. Phys. Conf. Ser., vol. 978, no. 1, 2018. https://doi.org/10.1088/1742-6596/978/1/012014

\section{BIOGRAPHY OF AUTHORS}

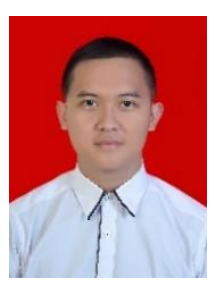

Yuda Prasetia was born on December 16, 1998, in Bengkulu (Sumatra, Indonesia). He is a student at Telkom University majoring in Informatics. The final project he chose to get a bachelor's degree is about the Internet of Things, specifically in the field of smart hydroponics. To do so, he joined the Cyber-Physical Systems Research Group. The $2^{\text {nd }}$ Sustainable Development Goals (SDG) regarding food security became his concern in completing this final project. Email: yudaaapras@student.telkomuniversity.ac.id 


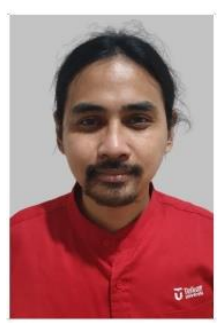

Aji Gautama Putrada received his bachelor's and master's degrees from Institut Teknologi Bandung (ITB) in 2008 and 2013. Since 2015 he has been a lecturer at the School of Informatics, Telkom University. In 2018 he was entrusted to be the coordinator of the Hardware and Embedded Systems Lab and since 2020 he has been appointed Vice Director of the Advanced and Creative Networks Research Center. He is active in several research grants given by the Ministry of Higher Education and the Ministry of Finance in the field of internet of things. Email: ajigps@ telkomuniversity.ac.id

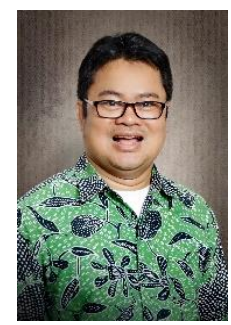

Andrian Rakhmatsyah received his bachelor's from Telkom University (was Telkom School of engineering) in 2001 and master's degrees from Institut Teknologi Bandung (ITB) in 2006. Since 2001 he has been a lecturer at the School of Informatics, Telkom University. Several positions have been entrusted to him from 2002 until 2019, such as head of informatics undergraduate study program in 2008 until 2010, as Head of Telematics (now, Cyber-Physical Systems) Research Group of Telkom School of Computing in 2014 until 2019. He is active in research in embedded system, internet of things and smart system. Email: kangandrian@telkomuniversity.ac.id 